\title{
Effectiveness of School-Based Management Practices in Increasing Community Participation and Implementing School Programs
}

\author{
Deitje Adolfien Katuuk*, Sjamsi Pasandaran, Theodorus Pangalila \\ Universitas Negeri Manado \\ Manado, Indonesia \\ *deitjekatuuk@unima.ac.id
}

\begin{abstract}
This study examines the effectiveness of SchoolBased Management (SBM) practices from two aspects, community participation, and school program implementation. The research conducted in 6 elementary schools in Tomohon which have implemented school-based management. This research applies evaluative study approach in which data are gathered by using an instrument formulated based on Assessment of School-Based Management Practices model. The data sources are 46 participants who consist of teachers, headmaster and school committees. Data are analyzed quantitatively and expressed in percentage. The findings indicate that the effectiveness of school-based management practices in increasing community participation and implementing school programs is significantly influenced from the availability and implementation of management policies, management guidelines, management programs, monitoring, and sustainable development program. It is recommended that strategic and programmatic policies need to be formulated to strengthen and increase the effectiveness of school-based management practices in schools.
\end{abstract}

\section{Keywords—implementation; school-based management}

\section{INTRODUCTION}

The effectiveness of school-based management is still a problem faced by many schools. Various studies have shown that there is an influence of the principal and leadership strategies on the effectiveness of SBM implementation [1]. Other studies have found that practical application of SBM will encourage and improve school performance [2]. There are also found results of research showing that SBM and Standard Based Accountability (SBA) have a positive effect on student achievement, either separately or jointly [3]. Effective school management strategies can improve student academic performances [4]. The strategy is mainly related to principal leadership and management skills. So many researchers consider that the effectiveness of SBM implementation will have an impact on school performance. Primarily related to three things that are improved educational outcomes for students, (2) Efficient delivery of services, (3) Increased opportunities for local decision-making [5]. The main idea of education-decentralization is giving authority and autonomy to school to improve efficiency, equity, and quality [6].
The various studies on SBM centered on factors influencing SBM and the impact of SBM on school performance and academic performance. Nevertheless, there is still little or no study on the effectiveness of SBM implementation regarding community participation, and in improving the effectiveness of the implementation of school programs. In practice, community participation is significant and can even be a criterion for successful implementation of SBM. There are several aspects to the problem that needs to be studied regarding community participation in school development from the planning, implementation, supervision and decision-making processes. In practice, it was observed that there was community participation through a container such as the School Committee. However, there is still little study on the effectiveness of participation and the effectiveness of that participation in the implementation of various school programs. Therefore, this study examines the effectiveness of SBM in increasing community participation, and implications for the development and improvement of school performance, especially in the implementation of school programs.

This research will add to the wealth of studies on the effectiveness of school management in increasing participation and in improving the effectiveness of the implementation of various school programs. Furthermore, it will increase scientific knowledge about strategic variables as an indicator of quality or indication of the effectiveness of SBM implementation. As a model of the study, this article raises awareness of the depth and breadth of the study on the effectiveness of SBM implementation both on the theoretical level and at the practical level of implementation.

\section{THEORETICAL}

In this research, it was understood that studies on the effectiveness of SBM implementation could be assessed from two scopes of effectiveness, i.e., study of influential strategic factors or variables, and study on the impact of SBM implementation. The study of these strategic factors can comprise first personal characteristics such as principals both leadership and academic qualifications and managerial skills. There are three models of SBM, the dominant model of the principal, the dominant model of teachers, and the predominant parent model [7]. Each of these models has a weakness that is 
the dominant model of the significant lack of space for participation of both teachers and parents and the community. Likewise, the dominant model of teachers lacks the space for parent and community participation. While the dominant model of parents even though giving space for participation but participation has not reached the broader community including stakeholders. Therefore, this study examines participation in a broader perspective covering the overall components of both school components such as principals and teachers, parent component, as well as community and stakeholder components. In developing countries, community participation in school management is still low [8]. According to Nishimura, community participation in SBM varies greatly depending on the activities and authorities provided [8] Community participation in school activities may include budgeting, educational and teaching development such as curriculum and learning, infrastructure maintenance and development, and monitoring and evaluation activities. This personal aspect is significant, supported by research findings that to improve the efficiency and effectiveness of school performance and quality there needs to be a change in the role of principals and teachers adapted to school-based management [9].

Second, the study of SBM implementation in this study is based on several propositions, namely SBM implementation depends on the adaptability of SBM with the situation of value system, sociology and culture considering SBM is a management model adopted from SBM model applied in developed countries [10]. In the implementation, also found a diversity of perceptions about SBM either because of conceptual understanding, implementation strategy, or because of socio-cultural factors. SBM as an innovative and new management model requires socialization to obtain a common perception and understanding of SBM itself. Determinant factors to the SBM implementation, implicate the conditions required for the effectiveness of SBM implementation in increasing the participation and implementation of the program.

\section{METHOD}

This study uses objective oriented evaluation approach that is to see the achievement of the SBM program that has been established as the goal. The study was conducted in six elementary schools in Tomohon City, North Sulawesi. The data source consists of 6 principals, 34 teachers, and six members of the School Committee. Data collection is done through observation, interview, questionnaire, and discussion. Observations are conducted in the form of participatory and structured observation. Aspect coverage of the instruments of data collection for participation consists of the participation of students, teachers, parents, school committees, and the involvement of the education office. Aspects of program implementation consist of the availability of management programs, planning documents, implementation, and supervision. Content validation and instrument construct are performed through expert judgment and validation test. Data were analyzed qualitatively with percentage count units.

\section{RESULT AND DISCUSSION}

The research findings show first, most respondents (73.26\%) rate that SBM is very useful in increasing school and community participation. The effectiveness is mainly seen in the private participation of schools, principals, teachers, and students. External participation is the prominent participation of parents through the School Committee and followed by the participation of the Education Office in Tomohon City. Participation forms include involvement in programming activities, namely development program planning, business participation and funding involving parents and school committees, participation in school program implementation, and participation in supervision through the School Committee. Second, the effectiveness of SBM in improving SBM program implementation in schools, most respondents, i.e., $87.39 \%$ rate advantageous. Implementation of the school program is primarily seen from the availability of complete programs and documents, program implementation as planned (having program implementation schedule), supervisory function implementation through school committee and periodic meeting at the end and beginning of school year between school and parent.

The findings of the study show some essential aspects of the effectiveness of SBM implementation in schools. First, it reinforces the substantive nature of SBM as an instrument and strategy for strengthening authority, autonomy, and empowerment, and school development [11]. An important indicator as a feature of SBM implementation effectiveness is both internal and external participation. The private participation of principals, teachers, and students points to the SBM model proposed by Leithwood \& Menzies. The findings of this study provide an illustration that SBM effectiveness is not only due to private participation, but also the participation of the community that is parents and stakeholders in Indonesia are embedded within the School Committee. Participation both internally and externally shows essential indicators of the measurement of participation both from the scope, level, and initiative participation. The scope of participation shows the breadth of participants' participation, while the level of participation indicates the level of the parties involved that includes all levels of elements associated with the school. Initiative participation refers to initiation efforts in school development. The findings of this research confirm that participatory initiatives will emerge if they can be fulfilled with some elements: (1) willingness, (2) ability, and (3) opportunity to participate. Meanwhile, from the nature of the findings, the findings of this study indicate that visible participation is still socio-nomic participation, i.e., participation driven by available opportunities, and by external factors primarily due to the influence of the school environment.

The breadth and level of participation in the implementation of SBM in schools have implications for the implementation of the program. Aspects of effective program implementation, related to (1) policies on management, (2) management programs, (3) socialization of management policies and programs, and (4) management guidelines. Nevertheless, the planning aspect is not strong enough to support the management of facilities and infrastructure, financing, and partnership cooperation with other institutions. 
Some aspects of the problem that needs to get attention are the management of facilities and infrastructure, financing and cooperation partnerships. These aspects of the problem are related to the availability and fulfillment of minimal service management standards. Katuuk has shown that there are some determinant factors on the effectiveness of SBM implementation in the implementation of the program in schools mainly related to contributory factors such as the availability of facilities and infrastructure, financial factors, and human resources available in this case the professional teachers [10].

\section{CONCLUSION}

Based on the results and discussion discussed above, it can be concluded (1) SBM is considered useful in increasing participation, especially the private participation of schools, especially principals and teachers. Participation is more driven by schools. (2) SBM is considered useful in improving the implementation of school programs in the planning, implementation, and supervision. The effectiveness of the program that is considered sufficient is related to the availability of planning documents, curriculum and learning process, and management of educators and education personnel. Nevertheless, there are components of the program that are less effective regarding infrastructure, financing, and cooperation. It is recommended to formulate strategic and programmatic policies that strengthen SBM implementation components in schools and strengthen the consistency of SBM policy implementation.

\section{ACKNOWLEDGMENTS}

The author would like to say thank to the rector of Manado State University.

\section{REFERENCES}

[1] G.V.S. Vally and K. Daud, "The implementation of school based management policy: an exploration," Procedia-Social and Behavioral Sciences. Elsevier, vol. 172, pp. 693-700, 2015.

[2] T. Sihono, and R. Yusof, "Implementation of School Based Management in Creating Effective Schools," International Journal of Independent Research and Studies, vol. 1, no. 4, pp. 142-152, 2012.

[3] I. Camminatiello, A. Paletta, and M.T. Speziale, "The effects of schoolbased management and standards-based accountability on student achievement: Evidence from pisa 2006," Electronic Journal of Applied Statistical Analysis, vol. 5, no. 3, pp. 381-386, 2012.

[4] J.T. Nzoka and J.A. Orodho, "School Management and Students' Academic Performance: How Effective are Strategies being Employed by School Managers in Secondary Schools in Embu North District, Embu County, Kenya?," International Journal of Humanities and Social Science, vol. 4, no. 9, pp. 86-99, 2014.

[5] H. Watson, Report on evaluation of school-based management. Canberra: Hugh Watson Consulting, 2004.

[6] J.R. Behrman, A.B. Deolalikar, and L.Y. Soon, "Conceptual issues in the role of education decentralization in promoting effective schooling in Asian Developing Countries," ERD Working Paper Series, no. 22, pp. $1-43,2002$.

[7] K. Leithwood and T. Menzies, "Forms and Effects of School-Based Management: A Review," Educational Policy, vol. 12, pp. 325-346, 1998.

[8] M. Nishimura, "Community Participation in School Management in Developing Countries," vol. 1, pp. 1-20, 2017.

[9] H.K. Yau and A. Lai Fong Cheng, "Principals and Teachers' perceptions of School policy as a key element of School-Based Management in Hong Kong Primary Schools," E Journal of Organizational Learning \& Leadership, vol. 9, no. 1, 2011.

[10] D.A. Katuuk, "Evaluation on School Based Management implementation in Elementary School at Tomohon City , North Sulawesi," vol. 5, no. 7, pp. 102-109, 2014.

[11] J. Hindriks, et al., "School autonomy and educational performance: within-country evidence," Université catholique de Louvain, Center for Operations Research and Econometrics (CORE), 2010. 